Article

\title{
Human Genotoxic Study Carried Out Two Years after Oil Exposure during the Clean-up Activities Using Two Different Biomarkers
}

Gloria Biern ${ }^{1}$, Jesús Giraldo ${ }^{2}$, Jan-Paul Zock 3,4,5, Gemma Monyarch ${ }^{1}$, Ana Espinosa ${ }^{3,4,5}$, Gema Rodríguez-Trigo ${ }^{6,7,8}$, Federico Gómez ${ }^{8,9}$, Francisco Pozo-Rodríguez ${ }^{8,10}$, Joan-Albert Barberà ${ }^{8,9}$ and Carme Fuster ${ }^{1, *}$

1 Unitat de Biologia Cel·lular i Genètica Mèdica, Facultat de Medicina, Universitat Autònoma de Barcelona (UAB), 08193-Bellaterra, Barcelona, Spain;

E-Mails: gloria.biern@gmail.com (G.B.); taguca@gmail.com (G.M.)

2 Unitat de Bioestadística i Institut de Neurociències, Facultat de Medicina, Universitat Autònoma de Barcelona (UAB), 08193-Bellaterra, Barcelona, Spain; E-Mail: jesus.giraldo@uab.es

3 Centre de Recerca en Epidemiologia Ambiental (CREAL), 08003-Barcelona, Spain; E-Mails: jpzock@creal.cat (J.-P.Z.); aespinosa@creal.cat (A.E.)

4 Universitat Pompeu Fabra, 08002-Barcelona, Spain

5 CIBER Epidemiología y Salud Pública (CIBERESP), 28029-Madrid, Spain

6 Servicio de Neumología, Hospital Clínico San Carlos, 28040-Madrid, Spain; E-Mail: grodriguezt@salud.madrid.org

7 Facultad de Medicina, Universidad Complutense, 28040-Madrid, Spain

8 CIBER Enfermedades Respiratorias (CIBERES), Bunyola, 07004-Mallorca, Spain; E-Mails: fpgomez@clinic.ub.es (F.G.); fpozo@h12o.es (F.P.-R.); jbarbera@clinic.ub.es (J.-A.B.)

9 Departamento de Medicina Respiratòria, Hospital Clínic-Institut d'Investigacions Biomèdiques August Pi I Sunyer (IDIBAPS), 08036-Barcelona, Spain

10 Departamento de Medicina Respiratoria, Unidad Epidemiologia Clínica, Hospital 12 de Octubre, 28047-Madrid, Spain

* Author to whom correspondence should be addressed; E-Mail: carme.fuster@uab.es; Tel.: +34-93-581-1273; Fax +34-93-581-1025.

Academic Editor: Merv Fingas

Received: 22 September 2015 / Accepted: 27 October 2015 / Published: 3 November 2015 


\begin{abstract}
Micronuclei, comet and chromosome alterations assays are the most widely used biomarkers for determining the genotoxic damage in a population exposed to genotoxic chemicals. While chromosome alterations are an excellent biomarker to detect short- and long-term genotoxic effects, the comet assay only measures early biological effects, and furthermore it is unknown whether nuclear abnormalies, such as those measured in the micronucleus test, remain detectable long-term after an acute exposure. In our previous study, an increase in structural chromosome alterations in fishermen involved in the clean-up of the Prestige oil spill, two years after acute exposure, was detected. The aim of this study is to investigate whether, in lymphocytes from peripheral blood, the nuclear abnormalies (micronucleus, nucleoplasmic bridges and nuclear buds) have a similar sensitivity to the chromosome damage analysis for genotoxic detection two years after oil exposure in the same non-smoker individuals and in the same peripheral blood extraction. No significant differences in nuclear abnormalies frequencies between exposed and non-exposed individuals were found $(p>0.05)$. However, chromosome damage, in the same individuals, was higher in exposed $v s$. non-exposed individuals, especially for chromosome lesions $(p<0.05)$. These findings, despite the small sample size, suggest that nuclear abnormalities are probably less-successful biomarkers than are chromosome alterations to evaluate genotoxic effects two or more years after an exposure to oil. Due to the great advantage of micronucleus automatic determination, which allows for a rapid study of hundreds of individuals exposed to genotoxic chemical exposure, further studies are needed to confirm whether this assay is or is not useful in long-term genotoxic studies after the toxic agent is no longer present.
\end{abstract}

Keywords: micronucleus test; chromosome damage; nuclear abnormities; chromosome alterations; oil exposure; genotoxicity; Prestige catastrophe

\title{
1. Introduction
}

Significant marine oil spills, approximately namely 14 accidents involving large oil tankers, have occurred in regions with a high population density in the last five decades [1,2]. When a sizeable spill occurs, there are usually a large number of individuals, in general local inhabitants, who collaborate in clean-up tasks to minimize the negative ecological and economic impact. So, for example, more than 300,000 people were involved in the clean-up activities after the wreck of the oil tanker Prestige, in November 2002. Although there are relatively few studies which have focused on the repercussions of acute oil exposure for human health, there is growing concern about the chemical exposure that clean-up activities involve and their potential health effects. Direct contact with oil or its vapors can cause skin rash and eye redness, and prolonged exposure can cause nausea, dizziness, headache, respiratory problems and psychiatric disorders [1,2]. Moreover, due to certain volatile organic oil compounds, in particular benzene, being carcinogenic in humans [3], it is very important to determine if exposure to oil during clean-up tasks is associated with genotoxic effects in the short- (less than 12 months) and long-term (more than one year). So far, only a few human genotoxic studies in oil exposed populations have been published, most after the wreck of the Prestige [4-14]. In general, these studies revealed 
increased genomic damage in exposed individuals during the clean-up tasks [4-11]. Nevertheless, only two research groups have carried out long-term genotoxic studies after oil exposure to the Prestige [12-15], with conflicting results. In one group, the authors described an increase of structural chromosome alterations in highly exposed vs. non-exposed individuals two and six years after exposure [12-14], this follow-up study reveal that chromosome damage persisted at least for the six years. Yet in another group, the study detected no genotoxic effects to be present seven years after exposure using other biomarkers (comet, micronucleus and T-cell receptor mutation assays) [15]. With the exception of T-cell receptor mutation assays, the sensibility of the two other biomarkers to detect long-term genotoxic effects has not been tested.

The micronucleus test, comet assay and chromosome alterations have been the most common biomarkers to determine genetic damage in any population exposed occupationally or environmentally to genotoxic chemicals, e.g., oil exposure during clean-up tasks [4-18]. A micronucleus is the result of chromosome breakage (acentric fragment) and/or loss (whole chromosome) caused by errors in DNA repair or in chromosome segregations not included in the main nucleus that are surrounded individually by the nuclear membrane [19]. The micronucleus test is performed by cytokinesis-block assays using cytochalasin B, which allows to be analyzed other nuclear abnormalies, such as nucleoplasmic bridges and nuclear buds in binuclear cells. The nucleoplasmic bridges indicate the occurrence of reorganizations in which chromatids or chromosomes are pulled to opposite poles during anaphase, resulting in dicentric or ring chromosomes. The nuclear buds are characterized by having the same morphology as a micronucleus, but they remain connected to the main nucleus and represent the process of elimination of amplified DNA or of the DNA repair complex and possibly excess chromosomes from aneuploid cells. Recently, it has been described that nucleoplasmic bridges and nuclear buds are also useful biomarkers for monitoring genetic damage by detecting and quantifying DNA damage and chromosome instability [20-23]. The comet biomarker is based on how a genotoxic agent will produce DNA-strand breaks and measures the extent of DNA migration in electrophoresis [24] and has been frequently used because it is a fast and easy method to assess DNA breaks with excellent sensitivity. Finally, chromosome alterations are any change in the normal structure or number of chromosomes. In general, their analyses for genotoxic studies include lesions (gaps and breaks of one or both chromatids) and structural alterations (such as acentric fragments, deletions, translocations, dicentrics, rings, marker chromosomes) resulting in direct DNA breakage, errors in synthesis or repair of DNA, and have been widely used biomarkers since the 1970s [16,23,24]. Although comet and nuclear anomaly assays are probably less resolute and less informative than is metaphasic chromosome analysis, in the last several years both tests have been used extensively in studies to evaluate genotoxic damage in large populations of exposed individuals because they are much easier and faster [19].

The evaluation of chromosome alterations requires cell cultures, while the evaluation of nuclear abnormalities requires cells in division but comet assay can be performed without the use of proliferative cells. For a long time, peripheral lymphocyte cultures have been the most widely employed in human genotoxic studies, however the introduction of nuclear abnormalities and comet assays as biomarkers allows for the use of alternative cell types, such as epithelial cells [25,26]. Epithelial cells can be used as early-effect biomarkers; nasal epithelial cells are replaced approximately once every 30 days and buccal epithelial cells one every 10-14 days [26] vs. peripheral blood lymphocytes, which serve as long-effect biomarkers and are renewed around every 4 to 6 years [27]. The great advantage of using, 
for example, buccal epithelial cells $v s$. lymphocytes is the easy and minimally invasive collection of samples, but the most important disadvantages are the discrepancies which come from using blood cells.

In contrast to the body of research regarding the use of different biomarkers to determine the genotoxic effect when the agent is present, there is scarce information to determine long-term effects after an acute exposure, with chromosome damage being the biomarker most frequently used. Given that the comet test indicates early biological effects [28,29]; it is probably not an ideal biomarker for long-term studies after acute genotoxic exposure. Although the usefulness of nuclear abnormalies, especially the micronucleus test, for short-term genotoxic studies is unquestionable, its sensibility for long-term studies, when the toxic agent is missing, has not been demonstrated yet. The main objective of this study is to determine whether nuclear abnormalies remain useful biomarkers for detecting genotoxic effects two years after Prestige oil exposure, comparing their results with those detected by chromosome alterations analyses.

\section{Material and Methods}

\subsection{Study Population}

The present study was performed on randomly selected subsamples of individuals included in a previous genotoxic study $[12,13]$. It was conducted using peripheral blood lymphocytes from individuals who had participated in clean-up activities of the Prestige oil spill. Only fishermen were included in our study in order to minimize other occupational sources of exposure that could act as confounders. A questionnaire survey including information about participation in clean-up tasks, health problems, lifestyle, history of cancer, medication, smoking status, fertility, age, and gender among 6780 fishermen one year after exposure was performed [30]. The selection criteria of individuals highly exposed and non-exposed to the oil was established from this information, described previously [30]. In brief, exposed local fishermen who participated for at least 15 days in clean-up activities of the Prestige oil spill, for four or more hours per day, during the first two months (when exposure presumably was greatest) were included as highly-exposed subjects for the study. Non-exposed individuals were selected from fishermen who had not participated in clean-up tasks for reasons other than those related to health. All exposed and non-exposed individuals were non-smokers (current smokers and ex-smokers were excluded), fertile and without a history of cancer, A new questionnaire and face-to-face interview, in order to verify the answers, was performed in a mobile unit that traveled to the participants' villages on the same day in which the samples were obtained two years after the spill. In the present work, a total of 20 exposed and 20 non-exposed individuals were studied, randomly selected from 91 exposed and 46 non-exposed individuals in which chromosome damage was analyzed [12,13]. Figure 1 shows the flow diagram of the study. The exposed group consisted of 9 men and 11 women with an average age of 48.2 years (ranging from 32.2 to 62.2 ; $\mathrm{SEM}=1.9$ ). The non-exposed group consisted of 3 men and 17 women with an average age of 53.1 years (ranging from 36.6 to 58.8; SEM = 1.3). No significant relationship between sex and group was found according to Fisher's exact test ( $p=0.0824$ ). The difference in age was found to be statistically significant both by Student's t-test and Wilcoxon sum of ranks. In principle, as a higher age could be associated with a higher propensity to present genotoxic abnormalities, the distribution of age in the sample could make it more difficult to statistically prove 
the association between abnormalities and oil exposure. Thus, because there are more older individuals included in the non-exposed group, age distribution should not favor the hypothesis of finding abnormalities in the exposed group. The collection, transport and processing of the samples were performed between 22 and 27 months after the Prestige disaster.

The project was approved by the Ethics Committee on Clinical Research of Galicia, and all participants provided written, informed consent.

Prestige oil spill (2002)

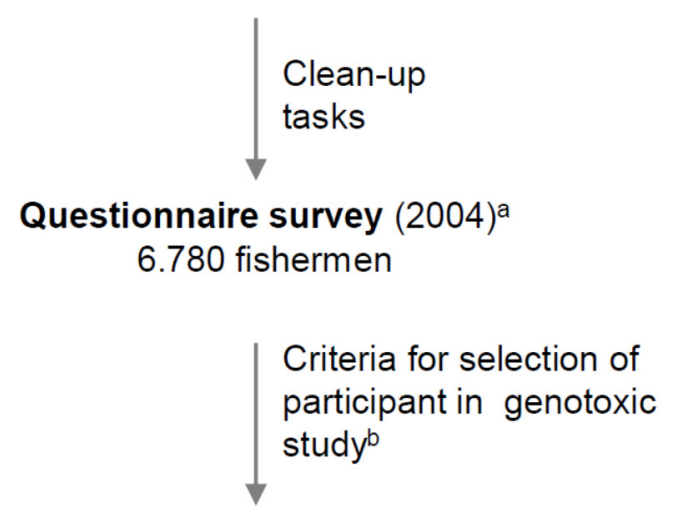

Genotoxic study $(2004 / 2005)^{b, c}$

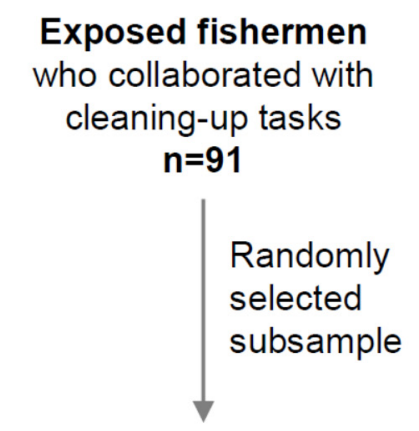

Non-exposed fishermen who did not participate in the cleaning-up tasks $\mathrm{n}=\mathbf{4 6}$

Randomly selected subsample

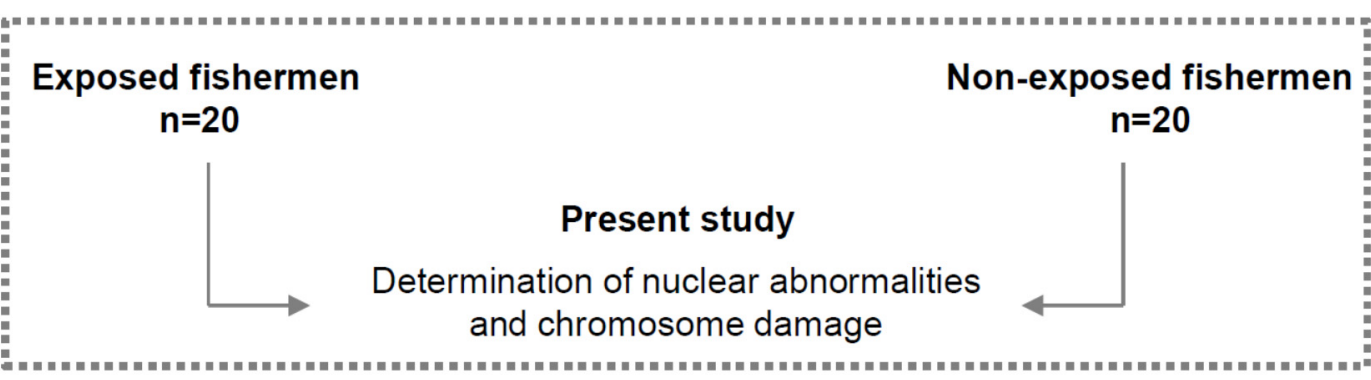

Figure 1. Flow diagram of the study. ${ }^{a}$ Detailed description in Zock et al. [30]; ${ }^{b}$ Detailed description in Rodriguez-Trigo et al. [12]; and ${ }^{\mathrm{c}}$ Detailed description in Monyarch et al. [13]. 


\subsection{Cytogenetic Analysis}

Peripheral blood was obtained in same extraction and later cultured at $37{ }^{\circ} \mathrm{C}$ in supplemented RPMI-1640 medium (GIBCO Invitrogen Cell Culture, Invitrogen; Carlsbad, CA, USA) according to standard procedures.

For the cytokinesis-block nuclear abnormalies test, peripheral blood was cultured, in duplicate, for $44 \mathrm{~h}$ and then cytochalasin-B was added to a final concentration of $6 \mu \mathrm{g} / \mathrm{mL}$. Cells were harvested by centrifugation after $72 \mathrm{~h}$ of culture and submitted to middle-hypotonic treatment with $0.075 \mathrm{mM} \mathrm{KCl}$ at $4{ }^{\circ} \mathrm{C}$. Cells were fixed in Carnoy (methanol-acetic acid 3:1 v/v), placed on dry slides, and stained with Leishman according to standard procedures. The micronucleus, nucleoplasmic bridges and nuclear buds in binucleated cells were identified according to the criteria of the HUMN project [31] and were evaluated by scoring 1000 binucleated cells (500 from each culture) using an Olympus Bx60 microscope. The cytogenetic-block proliferation index was calculated by the relation between total of cells with 1,2, 3 and 4 micronuclei $v s$. total of cells analyzed.

For chromosome breakage analyses involved in lesions and structural chromosome alterations, analyzed in published studies [12,13], peripheral blood was cultured, in duplicate, for $72 \mathrm{~h}$ and then harvested according to standard procedures. For chromosome lesions, a minimum at 100 metaphases were analyzed in each individual (50 from each culture). For structural chromosome alterations, at least 25 banded metaphases were karyotyped in each participant. Criteria for cytogenetic evaluations were determined according to the International System for Human Cytogenetic Nomenclature [32].

\subsection{Statistical Analysis}

A generalized estimating equation, GEE [12,13,33,34], was used for assessing the differences between the exposed and non-exposed groups for the micronucleus, nucleoplasmic bridges and nuclear buds, chromosome lesions and structural chromosome alterations. The GEE approach is an extension of generalized linear models designed to account for repeated, within-individual measurements. This method is particularly indicated for when the normality assumption is not reasonable, as happens, for instance, with discrete data. The GEE model was used instead of the classic Fisher exact test because the former takes into account the possible within-individual correlation, whereas the latter assumes that all observations are independent. Since several metaphases were analyzed per individual, the GEE model is more appropriate. Statistical significance was set at $p<0.05$. Statistical analyses were carried out with SAS/STAT release 9.02 (SAS Institute Inc.; Cary, NC, USA). The GEE model was fitted using the REPEATED statement in the GENMOD procedure. The conservative Type 3 statistics score was used for the analysis of the effects in the model. Sex and age were found not to be statistically significant when included in the GEE model and therefore were removed from the analysis.

\section{Results}

A satisfactory cell growth in all cultures was observed. A total of 40,000 binucleate cells, 4260 metaphases and 1100 karyotypes were analyzed in lymphocytes from exposed and non-exposed individuals respectively. All individuals had normal karyotypes (46,XX or 46,XY), except two cases, one with a polymorphic inversion of chromosome 9, inv(9)(p11q12), in an exposed individual (E14) and 
another case with an increased length of the heterochromatin on the long arm of the $\mathrm{Y}$ chromosome, $\mathrm{Yqh}+$, in a non-exposed individual (NE5).

Cell growth in cytochalasin-B cultures (from exposed and non-exposed individuals) showed a cytogenetic-block proliferation index ranging between $30 \%$ and $60 \%$. No significant statistical differences were found in the micronucleus or nuclear buds between exposed and non-exposed individuals $(p=0.4774$ and $p=0.2356$, respectively), and nucleoplasmic bridges were marginally influential $(p=0.08)$.

Chromosome lesions were higher in exposed rather than in non-exposed individuals $(p=0.0231)$, but structural chromosome alterations were only marginally $(p=0.0972)$. Marker chromosomes, unbalanced translocations and deletions were the structural chromosome alterations most frequently observed in both groups of individuals, and ring chromosomes and acentric fragments were only detected in exposed individuals. Numerical chromosome alterations (such as trisomies and monosomies) were excluded in these analyses because they can be attributed to the failure of the chromosome spread due to non-specific techniques having been applied to remaining cell membranes.

Table 1 and Figure 2 show the nuclear abnormalies (micronucleus, nucleoplasmic bridges and nuclear buds) and chromosome damage (lesions and structural alterations) observed in the same individuals. Cytogenetic results for each individual are found in Table 2, showing high inter-individual genotoxic variability for all biomarkers analyzed (micronucleus, nucleoplasmic bridges, nuclear buds, chromosome lesions and structural chromosome alterations) in exposed and in non-exposed individuals. With the exception of the degree of oil exposure no other associations were found between genotoxic damage and the different factors analyzed in the present study.

Table 1. Nuclear abnormalities and chromosome damage detected in same individuals exposed and non-exposed to oil.

\begin{tabular}{lccc}
\hline & Exposed & Non-Exposed & $\boldsymbol{p}$-Value \\
\hline Total Individuals, No. & 20 & 20 & \\
\hline Total Binucleate Cells, No. & 20.000 & 20.000 & \\
\hline Binucleated cells with micronucleus, No. (\%) & $457(2.3)$ & $514(2.6)$ & 0.4774 \\
\hline 1 micronucleus/cell, No. & 399 & 450 & \\
2 micronucleus/cell, No. & 49 & 53 & \\
3 micronucleus/cell, No. & 9 & 11 & \\
\hline Nucleplasmic bridges, No. (\%) & $131(0.65)$ & $98(0.49)$ & 0.08 \\
\hline Nuclear buds, No. (\%) & $106(0.53)$ & $68(0.34)$ & 0.2356 \\
\hline Total Metaphases Analyzed (Uniform Stain), No. & 2112 & 2.148 & \\
\hline Chromosome lesion, No. (\%) & $28(1.3)$ & $7(0.3)$ & 0.0231 \\
\hline Total Metaphases Karyotyped (G-Banded), No. & 537 & 563 & \\
\hline Structural chromosome alterations, No. (\%) & $36(6.7)$ & $16(2.8)$ & 0.0972 \\
\hline Balanced, No. & 1 & 3 & \\
Unbalanced, No. & 35 & 13 & \\
\hline
\end{tabular}



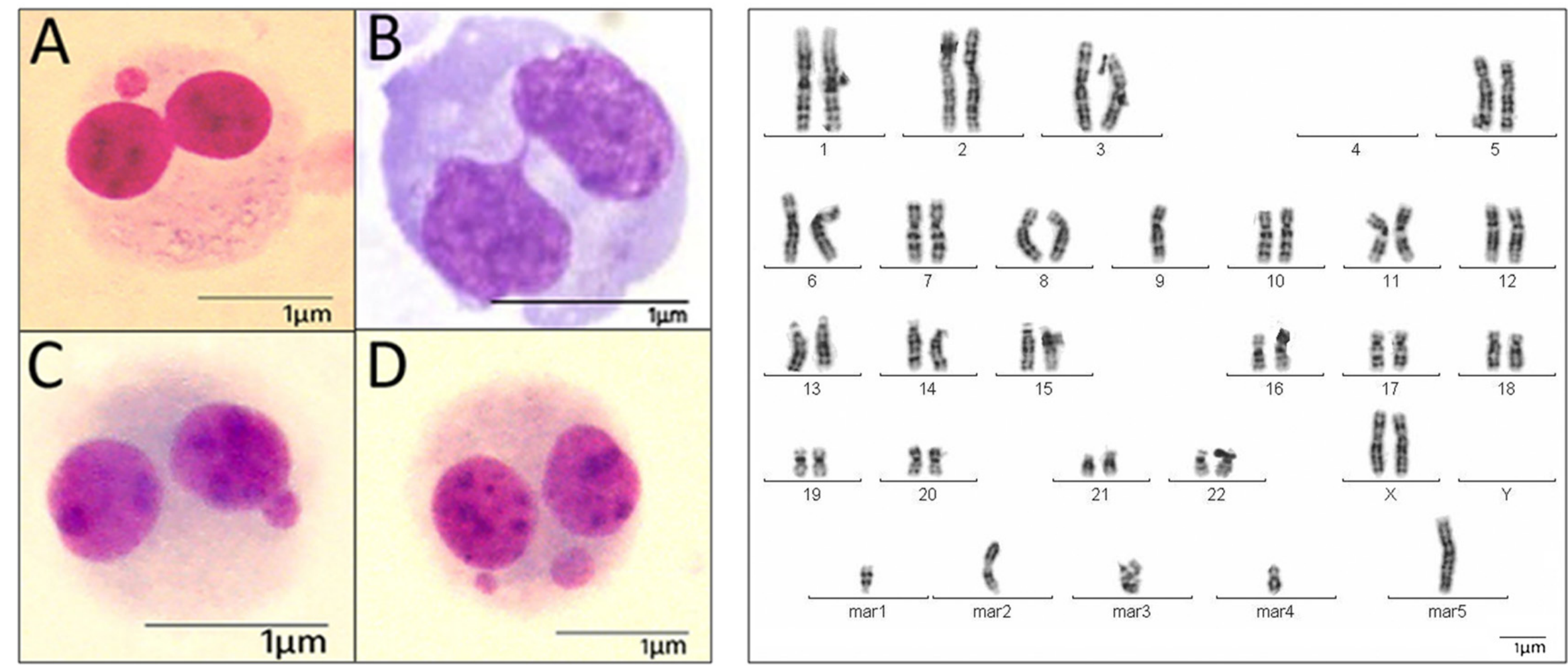

Figure 2. Genotoxic study using nuclear abnormalities and chromosome damage as biomarkers. Binuclear cells (left) showing: (A) one micronucleus, (B) nucleoplasmatic bridges, (C) nuclear buds, (D) two micronuclei; and Karyotype (right) with five marker chromosomes. 
Table 2. Cytogenetic results in individuals exposed and non-exposed to oil.

\begin{tabular}{|c|c|c|c|c|c|c|c|c|c|c|c|c|c|c|c|c|c|}
\hline \multirow{3}{*}{$\begin{array}{c}\text { Type of } \\
\text { individuals }\end{array}$} & \multirow{3}{*}{ Sex } & \multirow{3}{*}{ Age } & \multicolumn{8}{|c|}{ Binucleate cells } & \multicolumn{2}{|c|}{ Chromosomal Lesions } & \multicolumn{5}{|c|}{ Structural Chromosomal Alteration } \\
\hline & & & \multirow[t]{2}{*}{ Cells } & \multirow[b]{2}{*}{ MN } & \multicolumn{4}{|c|}{ MN } & \multirow[b]{2}{*}{ NBUP } & \multirow[b]{2}{*}{ NPB } & \multirow[b]{2}{*}{ Cells } & \multirow[b]{2}{*}{ Lesions } & \multirow[b]{2}{*}{ Karyotypes } & \multirow{2}{*}{$\begin{array}{l}\text { Structural } \\
\text { Alterations }\end{array}$} & \multirow{2}{*}{$\begin{array}{l}\text { Balanced } \\
\text { Structural } \\
\text { Alterations }\end{array}$} & \multirow{2}{*}{$\begin{array}{c}\text { Unbalanced } \\
\text { Structural } \\
\text { Alterations }\end{array}$} & \multirow[b]{2}{*}{ Type of Structural Alteration } \\
\hline & & & & & $\mathbf{0}$ & 1 & 2 & $\geq 3$ & & & & & & & & & \\
\hline \multicolumn{18}{|l|}{ Exposed } \\
\hline E1 & woman & 49.02 & 1000 & 29 & 971 & 27 & 2 & 0 & 4 & 7 & 100 & 1 & 27 & 5 & 0 & 5 & $\begin{array}{c}\mathrm{t}(13 ; 20)(\mathrm{q} 32 ; \mathrm{q} 12) ; \mathrm{t}(9 ; ?), \mathrm{t}(10 ; 18), \text { mar; } \\
\operatorname{del}(2)(\mathrm{q} 12)\end{array}$ \\
\hline E2 & man & 54,01 & 1000 & 23 & 977 & 20 & 3 & 0 & 2 & 4 & 116 & 3 & 28 & 0 & 0 & 0 & \\
\hline E3 & $\operatorname{man}$ & 44,02 & 1000 & 21 & 979 & 19 & 2 & 0 & 5 & 3 & 105 & 6 & 29 & 1 & 0 & 1 & ace \\
\hline $\mathrm{E} 4$ & $\operatorname{man}$ & 31,26 & 1000 & 17 & 983 & 16 & 1 & 0 & 7 & 1 & 105 & 2 & 25 & 2 & 0 & 2 & ace, ace \\
\hline E5 & woman & 51,90 & 1000 & 25 & 975 & 22 & 3 & 0 & 11 & 8 & 103 & 0 & 26 & 0 & 0 & 0 & \\
\hline E6 & $\operatorname{man}$ & 35,92 & 1000 & 17 & 983 & 16 & 1 & 0 & 3 & 8 & 108 & 1 & 30 & 2 & 0 & 2 & ace; $\operatorname{add}(12)($ qter $)$ \\
\hline E7 & woman & 49,62 & 1000 & 43 & 957 & 37 & 4 & 2 & 9 & 5 & 100 & 2 & 25 & 6 & 0 & 6 & ace; $\mathrm{t}(4 ; 16)(\mathrm{q} 13, \mathrm{p} 13.3)$; mar,mar,mar,mar \\
\hline E8 & $\operatorname{man}$ & 56,45 & 1000 & 43 & 957 & 37 & 4 & 2 & 19 & 6 & 102 & 1 & 29 & 0 & 0 & 0 & \\
\hline E9 & woman & 50,51 & 1000 & 11 & 989 & 9 & 2 & 0 & 16 & 14 & 100 & 6 & 26 & 1 & 0 & 1 & ace \\
\hline E10 & $\operatorname{man}$ & 52,50 & 1000 & 9 & 991 & 8 & 1 & 0 & 2 & 17 & 102 & 1 & 26 & 0 & 0 & 0 & \\
\hline E11 & woman & 54,86 & 1000 & 32 & 968 & 24 & 8 & 0 & 4 & 5 & 110 & 0 & 25 & 0 & 0 & 0 & \\
\hline E12 & woman & 44,89 & 1000 & 37 & 963 & 30 & 5 & 2 & 12 & 2 & 112 & 0 & 26 & 1 & 0 & 1 & mar \\
\hline E13 & $\operatorname{man}$ & 57,02 & 1000 & 18 & 982 & 18 & 0 & 0 & 9 & 3 & 100 & 1 & 31 & 1 & 1 & & $\mathrm{t}(13 ; 11)(\mathrm{p} 25 ; \mathrm{q} 23)$ \\
\hline E14 & woman & 46,13 & 1000 & 18 & 982 & 16 & 1 & 1 & 7 & 3 & 104 & 1 & 26 & 1 & 0 & 1 & $\operatorname{mar}$ \\
\hline E15 & woman & 62,17 & 1000 & 14 & 986 & 11 & 3 & 0 & 4 & 3 & 103 & 0 & 25 & 3 & 0 & 3 & $\mathrm{t}(7 ; 10) ; \mathrm{r}, \mathrm{r}$ \\
\hline E16 & woman & 48,99 & 1000 & 10 & 990 & 8 & 2 & 0 & 1 & 1 & 112 & 0 & 25 & 1 & 0 & 1 & $\mathrm{t}(\mathrm{X} ; 4)(\mathrm{q} 21 ; \mathrm{p} 16)$ \\
\hline E17 & woman & 58,37 & 1000 & 8 & 992 & 8 & 0 & 0 & 1 & 3 & 105 & 0 & 27 & 1 & 0 & 1 & $\operatorname{del}(7)(q 33)$ \\
\hline E18 & woman & 36,90 & 1000 & 31 & 969 & 26 & 3 & 2 & 4 & 4 & 112 & 0 & 30 & 1 & 0 & 1 & mar \\
\hline E19 & $\operatorname{man}$ & 52,98 & 1000 & 38 & 962 & 34 & 4 & 0 & 5 & 6 & 106 & 2 & 26 & 1 & 0 & 1 & $\operatorname{del}(7)(\mathrm{p} 15)$ \\
\hline \multirow[t]{2}{*}{$\mathrm{E} 20$} & $\operatorname{man}$ & 54,94 & 1000 & 13 & 987 & 13 & 0 & 0 & 6 & 3 & 107 & 1 & 25 & 9 & 0 & 9 & mar,mar; ace, ace; mar, mar,mar,mar,mar \\
\hline & & & 20000 & 457 & 19543 & 399 & 49 & 9 & 131 & 106 & 2112 & 28 & 537 & 36 & 1 & 35 & \\
\hline
\end{tabular}


Table 2. Cont.

\begin{tabular}{|c|c|c|c|c|c|c|c|c|c|c|c|c|c|c|c|c|c|}
\hline $\begin{array}{c}\text { Non- } \\
\text { Exposed }\end{array}$ & & & & & & & & & & & & & & & & & \\
\hline NE1 & woman & 54,33 & 1000 & 22 & 978 & 19 & 3 & 0 & 3 & 0 & 103 & 0 & 25 & 0 & 0 & 0 & \\
\hline NE2 & woman & 50,60 & 1000 & 22 & 978 & 17 & 4 & 1 & 0 & 0 & 100 & 3 & 34 & 0 & 0 & 0 & \\
\hline NE3 & woman & 57,52 & 1000 & 13 & 987 & 10 & 2 & 1 & 4 & 2 & 105 & 0 & 25 & 4 & 0 & 4 & mar,mar,mar,mar \\
\hline NE4 & woman & 57,19 & 1000 & 14 & 986 & 13 & 1 & 0 & 16 & 0 & 101 & 1 & 25 & 1 & 0 & 1 & $\operatorname{del}(1)(\mathrm{q} 21)$ \\
\hline NE5 & $\operatorname{man}$ & 58,78 & 1000 & 22 & 978 & 19 & 2 & 1 & 1 & 8 & 108 & 0 & 26 & 3 & 0 & 3 & $\operatorname{del}(2)(\mathrm{q} 21) ; \operatorname{del}(1)(\mathrm{q} 23), \operatorname{mar}$ \\
\hline NE6 & woman & 57,61 & 1000 & 59 & 941 & 52 & 6 & 1 & 2 & 6 & 100 & 0 & 25 & 1 & 1 & 0 & $\mathrm{t}(13 ; 14)(\mathrm{q} 14, \mathrm{q} 32)$ \\
\hline NE7 & woman & 36,56 & 1000 & 5 & 995 & 3 & 2 & 0 & 5 & 7 & 107 & 0 & 25 & 1 & 0 & 1 & $\operatorname{del}(1)(\mathrm{q} 32)$ \\
\hline NE8 & woman & 53,22 & 1000 & 30 & 970 & 26 & 3 & 1 & 1 & 7 & 110 & 0 & 33 & 1 & 0 & 1 & mar \\
\hline NE9 & woman & 58,58 & 1000 & 50 & 950 & 43 & 6 & 1 & 5 & 1 & 113 & 0 & 43 & 0 & 0 & 0 & \\
\hline NE10 & woman & 56,00 & 1000 & 26 & 974 & 22 & 1 & 3 & 9 & 1 & 107 & 0 & 26 & 0 & 0 & 0 & \\
\hline NE11 & woman & 56,85 & 1000 & 10 & 990 & 10 & 0 & 0 & 3 & 4 & 120 & 1 & 25 & 1 & 0 & 1 & mar \\
\hline NE12 & woman & 46,36 & 1000 & 38 & 962 & 32 & 5 & 1 & 9 & 5 & 130 & 0 & 26 & 0 & 0 & 0 & \\
\hline NE13 & woman & 55,82 & 1000 & 12 & 988 & 10 & 2 & 0 & 2 & 6 & 101 & 0 & 25 & 0 & 0 & 0 & \\
\hline NE14 & woman & 45,84 & 1000 & 26 & 974 & 24 & 2 & 0 & 8 & 4 & 108 & 2 & 25 & 0 & 0 & 0 & \\
\hline NE15 & man & 48,56 & 1000 & 41 & 959 & 33 & 7 & 1 & 8 & 3 & 107 & 0 & 25 & 0 & 0 & 0 & \\
\hline NE16 & woman & 55,54 & 1000 & 23 & 977 & 23 & 0 & 0 & 5 & 2 & 102 & 0 & 26 & 0 & 0 & 0 & \\
\hline NE17 & woman & 58,62 & 1000 & 36 & 964 & 32 & 4 & 0 & 8 & 4 & 112 & 0 & 26 & 1 & 0 & 1 & $\operatorname{del}(9)(\mathrm{q} 21)$ \\
\hline NE18 & $\operatorname{man}$ & 57,15 & 1000 & 38 & 962 & 37 & 1 & 0 & 6 & 3 & 105 & 0 & 43 & 0 & 0 & 0 & \\
\hline NE19 & woman & 49,98 & 1000 & 18 & 982 & 16 & 2 & 0 & 3 & 1 & 108 & 0 & 26 & 2 & 1 & 1 & $\mathrm{t}(8 ; 13)((\mathrm{q} 24.1 ; \mathrm{q} 31) ; \mathrm{t}(2 ; 5)$ \\
\hline \multirow[t]{2}{*}{ NE20 } & woman & 46,31 & 1000 & 9 & 991 & 9 & 0 & 0 & 0 & 4 & 101 & 0 & 29 & 1 & 1 & 0 & $\mathrm{t}(3 ; 8)(\mathrm{q} 27 ; \mathrm{q} 13)$ \\
\hline & & & 20000 & 514 & 19486 & 450 & 53 & 11 & 98 & 68 & 2148 & 7 & 563 & 16 & 3 & 13 & \\
\hline
\end{tabular}

Abbreviations: ace: acentric fragment; add: additional material of unknown origin; del: deletion; mar: marker chromosome; p: short arm; q: long arm; qter: terminal long arm; t: translocation; MN: micronuclei; NBUP: nucleoplasmic bridges; NPB: nuclear buds. Commas indicate the beginning of new metaphase. 


\section{Discussion}

Toxic agents can induce complex changes in the genome, and to-date there is no single biomarker to detect all types of these alterations, probably due to different molecular mechanisms being involved $[29,35,36]$. It is therefore probable that not all genotoxic biomarkers are equally useful for long-term evaluation after exposure.

To date, very few long-term genotoxic studies after an accidental oil exposure have been previously published [12-15]. In all of these studies only individuals highly exposed to oil were included, yet the findings obtained were not coincident. While an increase of structural chromosome alterations in exposed individuals two and six years after exposure was observed [12-14], no genotoxic effects using other biomarkers (comet, micronucleus and T-cell receptor mutation assays) after seven years were detected [15]. The T-cell receptor mutation assay, used in Laffon's study [15], is an excellent biomarker for long-term studies because it provides information about the genotoxic effect which have occurred several months to several years after exposure [37]. However, the comet assay, also a successful biomarker employed by the authors, indicates early biological effects [28,29], so is probably not the most suitable test to evaluate long-term genotoxic effects. In relation to nuclear abnormalies, with the exception of Laffon et al. [15] and the present study, no other long-term genotoxic analyses have been performed, and in both studies no genotoxicity was detected two and seven years after oil exposure. Thus, we are not sure that this biomarker is still valid for long-term analysis.

The main differences in the above referred studies [12-15] were the individuals included in the study, the time following oil exposure (two, six and seven years), and the biomarkers used (mainly chromosome damage $v s$. micronuclei and nuclear abnormalies). In order to minimize the dispersion of these factors, we have analyzed these same biomarkers two years after oil exposure in the same individuals in which chromosome alterations were observed. Our results showed no differences in micronuclei and nuclear abnormalies between those exposed and non-exposed to oil. Thus, if we had only used these biomarkers, our findings would have suggested that the genotoxic effect has disappeared two years after oil exposure, long before the seven years as described Laffon et al. [15] However, the present study shows an increase of chromosome damage in the same exposed individuals, in which no differences for nuclear abnormalies were found, indicating that genotoxic damage does persist two years after acute oil exposure. Additionally, an increase of chromosome damage in a high number of exposed individuals was previously reported two and six years after oil exposure [12-14]. Despite the very strict selection criteria for exposed individuals and the small sample size analyzed, the present findings, supported by those reported previously [12-15], suggest that micronuclei and nuclear abnormalies are probably less-successful biomarkers than are chromosome damage to evaluate genotoxic effect more than two years after acute oil exposure when the toxic agent is no longer present. Moreover, our results indicate that chromosome damage is more informative than micronuclei and nuclear abnormalies because acentric fragments (which corresponds to the origin of the micronucleus) and ring chromosomes (corresponding to nucleoplasmic bridges) were detected in exposed individuals two years after oil exposure. It is relevant to note that smokers were excluded in present study because an association between smoking and chromosome damage has been described $[33,38]$. Finally, due to the fact that the micronucleus test and other nuclear abnormalies can be detected automatically versus chromosome analysis, and moreover this test is much easier, faster and allows for analysis of a large number of cells and does not require as 
much extensive personnel training, further studies are needed to confirm these preliminary results in larger samples.

\section{Conclusions}

To date, no information has been published regarding whether the micronucleus test remains suitable several years after the toxic agent is no longer present. For this reason, in the present study we evaluated the utility of nuclear abnormalies, including micronucleus test, to assess the genotoxic oil effect two years after the wreck of the Prestige comparing these results with those obtained from chromosome alterations analyses in the same non-smoker individuals and in the same peripheral blood extraction. Our results showed no differences in nuclear abnormalies between those exposed and non-exposed, however the chromosome damage was higher in exposed individuals. These features were compared with previous a report derived from long-term genotoxic studies after an accidental oil exposure. The main findings are:

- nuclear abnormalies (micronucleus, nucleoplasmic bridges and nuclear buds) in binucleated cells may not detect genotoxic effects more than two years after acute oil exposure when the toxic agent is no longer present;

- chromosome damage (chromosome lesion and structural chromosome alterations) in metaphases cells is a useful biomarker for assessing genotoxic effect two years after acute oil exposure using the same peripheral blood extraction in which nuclear abnormalies were analyzed; and

- comparative study using nuclear abnormalies and chromosome damage analyses emphasizes the need to use appropriate biomarker for detection of genotoxic effect in individuals involved in toxic accidents.

Despite the reduced number of individual analyzed, the present study suggests that micronuclei and nuclear abnormalies are probably less-successful biomarkers for the evaluation of long-term genotoxic oil effects when the toxic agent is no longer present. However, due to the fact that with the micronucleus test these and other nuclear abnormalies can be detected automatically, further studies are needed to confirm these preliminary results.

\section{Acknowledgments}

The kind participation of the fishermen's cooperatives and the efforts made by Antonio Devesa are gratefully acknowledged. The authors wish to thank Ana Souto Alonso, Marisa Rodríguez Valcárcel, Luisa Vázquez Rey, Emma Rodríguez (Complexo Hospitalario Universitario A Coruña), and Ana Utrabo, Angels Niubó (Universitat Autònoma de Barcelona). The investigators are greatly indebted to J. Ancochea and J.L. Alvarez-Sala, past presidents of SEPAR, for their initiative and support. For this study, grants were provided from the Health Institute Carlos III FEDER (PI03/1685), Sociedad Española de Neumología y Cirugía Torácica (SEPAR), Cowmissionat per a Universitats I Recerca from Generalitat de Catalunya (14SGR903), Centro de Investigación en Red de Enfermedades Respiratorias (CIBERES). The different sponsors were not involved in the design of the study, sample collection, cytogenetic analysis, or interpretation of the data or preparation/revision of the manuscript. 


\section{Author Contributions}

Conception and design of the experiments: C.F. Analysis and interpretation of the data: G.B., G.M., C.F. Statistical analysis: J.G., A.E., J.P.Z. Composition and revision of the manuscript: J.G., J.P.Z., G.R.T., F.P.G., F.P.R., J.A.B. and C.F.

\section{Conflicts of Interest}

The authors declare no conflict of interest.

\section{References}

1. Aguilera, F.; Méndez, J.; Pásaro, E.; Laffon, B. Review of the effects of exposure to spilled oils on human health. J. Appl. Toxicol. 2010, 30, 291-301.

2. Goldstein, B.D.; Osofsky, H.J.; Lichtveld, M.Y. The Gulf oil spill. N. Engl. J. Med. 2011, 364, 1334-1348.

3. IARC. Occupational Exposures in Petroleum Refining: Crude Oil and Major Petroleum Fuels IARC. Monographs on the Evaluations of Carcinogenic Risk to Humans; International Agency for Research on Cancer: Lyon, France, 1989; Volume 45.

4. Clare, M.G.; Yardley-Jones, A.; Maclean, A.C.; Dean, B.J. Chromosome analysis from peripheral blood lymphocytes of workers after an acute exposure to benzene. Br. J. Ind. Med. 1984, 41, 249-253.

5. Cole, J.; Beare, D.M.; Waugh, A.P.; Capulas, E.; Aldridge, K.E.; Arlett, C.F.; Green, M.H.; Crum, J.E.; Cox, D.; Garner, R.C.; et al. Biomonitoring of possible human exposure to environmental genotoxic chemicals: Lessons from a study following the wreck of the oil tanker Braer. Environ. Mol. Mutagen. 1997, 30, 97-111.

6. Laffon, B.; Fraga-Iriso, R.; Perez-Cadahia, B.; Méndez, J. Genotoxicity associated to exposure to Prestige oil during autopsies and cleaning of oil-contaminated birds. Food Chem. Toxicol. 2006, 44, 1714-1723.

7. Perez-Cadahia, B.; Laffon, B.; Pasaro, E.; Méndez, J. Genetic damage induced by accidental environmental pollutants. Sci. World J. 2006, 6, 1221-1237.

8. Pérez-Cadahía, B.; Lafuente, A.; Cabaleiro, T.; Pasaro, E.; Méndez, J.; Laffon, B. Initial study on the effects of Prestige oil on human health. Environ. Int. 2007, 33, 176-185.

9. Pérez-Cadahía, B.; Laffon, B.; Porta, M. Relationship between blood concentrations of heavy metals and cytogenetic and endocrine parameters among subjects involved in cleaning coastal areas affected by the Prestige tanker oil spill. Chemosphere 2008, 7, 447-455.

10. Pérez-Cadahía, B.; Laffon, B.; Valdiglesias, V.; Pasaro, E.; Mendez, J. Cytogenetic effects induced by Prestige oil on human populations: The role of polymorphisms in genes involved in metabolism and DNA repair. Mutat. Res. 2008, 653, 117-123.

11. Perez-Cadahia, B.; Mendez, J.; Pasaro, E.; Lafuente, A.; Cabaleiro, T.; Laffon, B. Biomonitoring of human exposure to Prestige oil: Effects on DNA and endocrine parameters. Environ. Health Insights 2008, 2, 83-92. 
12. Rodríguez-Trigo, G.; Zock, J.P.; Pozo-Rodríguez, F.; Gómez, F.P.; Monyarch, G.; Bouso, L.; Coll, M.D.; Verea, H.; Antó, J.M.; Fuster, C.; et al. SEPAR-Prestige Study Group. Health changes in fishermen 2 years after clean-up of the Prestige oil spill. Ann. Intern. Med. 2010, 153, 489-498.

13. Monyarch, G.; de Castro-Reis, F.; Zock, J.P.; Giraldo, J.; Pozo-Rodríguez, F.; Espinosa, A.; Rodríguez-Trigo, G.; Verea, H.; Castaño-Vinyals, G.; Gómez, F.P.; et al. Chromosomal bands affected by acute oil exposure and DNA repair errors. PLoS ONE 2013, 8, e81276.

14. Hildur, K.; Templado, C.; ZocK, J.P.; Giraldo, J.; Pozo-Rodríguez, F.; Frances, A.; Monyarch, G.; Rodríguez-Trigo, G.; Rodriguez-Rodriguez, E.; Souto, A.; et al. Follow-up genotoxic study: Chromosome damage two and six years after exposure to the Prestige oil spill. PLoS ONE 2015, 10, doi:10.1371/journal.pone.0132413.

15. Laffon, B.; Aguilera, F.; Ríos-Vázquez, J.; Valdiglesias, V.; Pásaro, E. Follow-up study of genotoxic effects in individuals exposed to oil from the tanker Prestige, seven years after the accident. Mutat. Res. 2014, 760, 10-16.

16. Mateuca, R.; Lombaert, N.; Aka, P.V.; Decordier, I.; Kirsch-Volders, M. Chromosomal changes: Induction, detection methods and applicability in human biomonitoring. Biochimie 2006, 88, 1515-1531.

17. Valverde, M.; Rojas, E. Environmental and occupational biomonitoring using the Comet assay. Mutat. Res. 2009, 681, 93-109.

18. DeMarini, D.M. Genotoxicity biomarkers associated with exposure to traffic and near-road atmospheres: A review. Mutagenesis 2013, 28, 485-505.

19. Fenech, M.; Kirsch-Volders, M.; Rossnerova, A.; Sram, R.; Romm, H.; Bolognesi, C.; Ramakumar, A.; Soussaline, F.; Schunck, C.; Elhajouji, A.; et al. HUMN project initiative and review of validation, quality control and prospects for further development of automated micronucleus assays using image cytometry systems. Int. J. Hyg. Environ. Health 2013, 216, 541-552.

20. Norppa, H.; Bonassi, S.; Hansteen, I.L.; Hagmar, L.; Strömberg, U.; Rössner, P.; Boffetta, P.; Lindholm, C.; Gundy, S.; Lazutka, J.; et al. Chromosomal aberrations and SCEs as biomarkers of cancer risk. Mutat. Res. 2006, 600, 37-45.

21. Bonassi, S.; Norppa , H.; Ceppi, M.; Strömberg, U.; Vermeulen, R.; Znaor, A.; Cebulska-Wasilewska, A.; Fabianova, E.; Fucic, A.; Gundy, S.; et al. Chromosomal aberration frequency in lymphocytes predicts the risk of cancer: Results from a pooled cohort study of 22,358 subjects in 11 countries. Carcinogenesis 2008, 29, 1178-1183.

22. Fenech, M.; Kirsch-Volders, M.; Natarajan, A.T.; Surralles, J.; Crott, J.W.; Parry, J.; Norppa, H.; Eastmond, D.A.; Tucker, J.D.; Thomas, P. Molecular mechanisms of micronucleus, nucleoplasmic bridge and nuclear bud formation in mammalian and human cells. Mutagenesis 2011, 26, 125-132.

23. Kirsch-Volders, M.; Bonassi, S.; Knasmueller, S.; Holland, N.; Bolognesi, C.; Fenech; M.F. Commentary: Critical questions, misconceptions and a road map for improving the use of the lymphocyte cytokinesis-block micronucleus assay for in vivo biomonitoring of human exposure to genotoxic chemicals-A HUMN project perspective. Mutat. Res. 2014, 759, 49-58.

24. Azqueta, A.; Collins, A.R. The essential comet assay: A comprehensive guide to measuring DNA damage and repair. Arch. Toxicol. 2013, 87, 949-968. 
25. Torres-Bugarín, O.; Zavala-Cerna, M.G.; Nava, A.; Flores-García, A.; Ramos-Ibarra, M.L. Potential Uses, Limitations, and Basic Procedures of Micronuclei and Nuclear Abnormalities in Buccal Cells. Dis. Markers 2014, 2014, doi:10.1155/2014/956835.

26. Rojas, E.; Lorenzo,Y.; Haug, K.; Nicolaissen, B.; Valverde, M. Epithelial cells as alternative human biomatrices for comet assay. Front. Genet. 2014, 5, doi:10.3389/fgene.2014.00386.

27. Sprent, J.; Tough, D.G. Turnover of native and memry phenotype T cells. J. Exp. Med. 1994, 179, 1127-1135.

28. Dusinska, M.; Collins, A.R. The comet assay in human biomonitoring: Gene-environment interactions. Mutagenesis 2008, 23, 191-205.

29. Anderson, D.; Dhawan, A.; Laubenthal, J. The comet assay in human biomonitoring. Methods Mol. Biol. 2013, 1044, 347-362.

30. Zock, J.P.; Rodriguez-Trigo, G.; Pozo-Rodriguez, F.; Barberà, J.A.; Bouso, L.; Torralba, Y.; Antó, J.M.; Gómez, F.P.; Fuster, C.; Verea, H.; et al. Prolonged respiratory symptoms in clean-up workers of the Prestige oil spill. Am. J. Respir. Crit. Care Med. 2007, 176, 610-616.

31. Fenech, M. Cytokinesis-block micronucleus cytome assay. Nat. Protoc. 2007, 2, 1084-1104.

32. ISCN. An International System for Human Cytogenetic Nomenclature; Shafer, L.G., McGowan-Jordan, J., Schmid, M., Eds.; S. Karger: Basel, Switzerland, 2013.

33. Liang, K.Y.; Zeger, S.L. Longitudinal data analysis using generalized linear models. Biometrika 1986, 73, 13-22.

34. De la Chica, R.A; Ribas, I.; Giraldo, J.; Egozcue, J.; Fuster, C. Chromosomal instability in amniocytes from fetuses of mothers who smoke. JAMA 2005, 293, 1212-1222.

35. Thompson, S.L.; Compton, D.A. Chromosomes and cancer cells. Chromosome Res. 2011, 19, 433-444.

36. Luzhna, L.; Kathiria, P.; Kovalchuk, O. Micronuclei in genotoxicity assessment: From genetics to epigenetics and beyond. Front. Genet. 2013, 4, 131.

37. Ishioka, N.; Umeki, S.; Hirai, Y.; Akiyama, M.; Kodama, T.; Ohama, K.; Kyoizumi, S. Stimulated rapid expression in vitro for early detection of in vivo T-cell receptor mutations induced by radiation exposure. Mutat. Res. 1997, 390, 269-282.

38. Littlefield, L.G.; Joiner, E.E. Analysis of chromosome aberrations in lymphocytes of long-term heavy smokers. Mutat. Res. 1986, 170, 145-150.

(C) 2015 by the authors; licensee MDPI, Basel, Switzerland. This article is an open access article distributed under the terms and conditions of the Creative Commons Attribution license (http://creativecommons.org/licenses/by/4.0/). 